\title{
Proteus myxofaciens
}

National Cancer Institute

\section{Source}

National Cancer Institute. Proteus myxofaciens. NCI Thesaurus. Code C86687.

A species of facultatively anaerobic, Gram-negative, rod shaped bacteria assigned to the phylum Proteobacteria. This species is motile, methyl red, catalase, Voges-Proskauer test, citrate, urease, and lipase positive, hemolytic, indole and oxidase negative, does not produce hydrogen sulfide, reduces nitrate, and hydrolyzes gelatin but not esculin. P. myxofaciens is part of the normal human and animal intestinal flora and is widespread in the environment, but can also be an opportunistic pathogen in humans causing nosocomial, urinary tract, and wound infections. 